\title{
Complete urethral injury in the penile fracture: a case report and literature review
}

\author{
Guangju Ge", Huan Wang", Yuanlei Chen, Gonghui Li, Liang Ma \\ Department of Urology, Sir Run Run Shaw Hospital, Zhejiang University School of Medicine, Hangzhou, China \\ \#These authors contributed equally to this work. \\ Correspondence to: Professor Liang Ma. Department of Urology, Sir Run Run Shaw Hospital, Zhejiang University School of Medicine, 3 Qinchun \\ East Road, Jianggan District, Hangzhou, China. Email: maliang0110@zju.edu.cn.
}

\begin{abstract}
Penile fracture is described as a traumatic rupture of the tunica albuginea caused by blunt injury to the erect penis. It usually occurs as a single rupture of the tunica albuginea in one of two corpora cavernosa; a rupture with urethral injury is an extremely rare condition. Although its diagnosis is usually clinical, ultrasound plays an important role in confirming diagnosis and identifying the site of the injury. Here, we presented a case of penile fracture with complete urethral injury. A 43-year-old male was admitted to the hospital because of trauma to the genital and dysuria following sexual intercourse. After admission, the patient was diagnosed with double penile fracture and complete urethral injury after the physical and B-ultrasound examinations. Emergency surgery to remove the hematoma and repair the urethra was performed. The patient recovered smoothly and was discharged on the third day after operation. After two months' follow-up, the patient urinated smoothly and achieved an adequate erection without other complications. In this case, consistent with previous studies, emergency surgery for penile fracture is necessary and can preserve the urethral function and sexual function. In addition, there are two lesions in tunica albuginea in this case, so careful search for the penile shaft during the surgery is important to avoid the missed injuries. This report provides evidence of an uncommon and underreported clinical case.
\end{abstract}

Keywords: Penile fracture; urethral injury; emergency surgery; case report

Submitted Aug 09, 2020. Accepted for publication Oct 28, 2020.

doi: $10.21037 /$ tau-20-1155

View this article at: http://dx.doi.org/10.21037/tau-20-1155

\section{Introduction}

Penile fracture is defined as the rupture of the tunica albuginea of the corpus cavernosum caused by blunt trauma to the erect penis (1). The major reason of penile fractures is direct trauma during sexual intercourse. Penile fractures usually present with a cracking sound with concomitant sudden swelling and ecchymosis of the penis followed by rapid detumescence (2). Penile fracture accompanied with the urethral injury is not common, especially with the complete urethral injury (3). Concurrent urethral injury is present in $0-38 \%$ of cases $(4,5)$. Complications of the penile fracture include coital difficulty, urethral fistula, penile plaque, and erectile dysfunction (4).

Controversies are raised regarding the optimal management of penile fracture. For minimal lesion, conservative treatment was advocated. Muentener et al. indicated that conservative therapy restricted to uncomplicated cases led to an equally good outcome compared with the surgery treatment (5). Other opinions advocated that immediate surgical repair was superior to nonoperative treatment in the management of penile fracture (2). However, for the penile fracture with complete urethral injury, previous researches lacked detailed description. This work aimed to assess the incision ways and effects of immediate surgery 

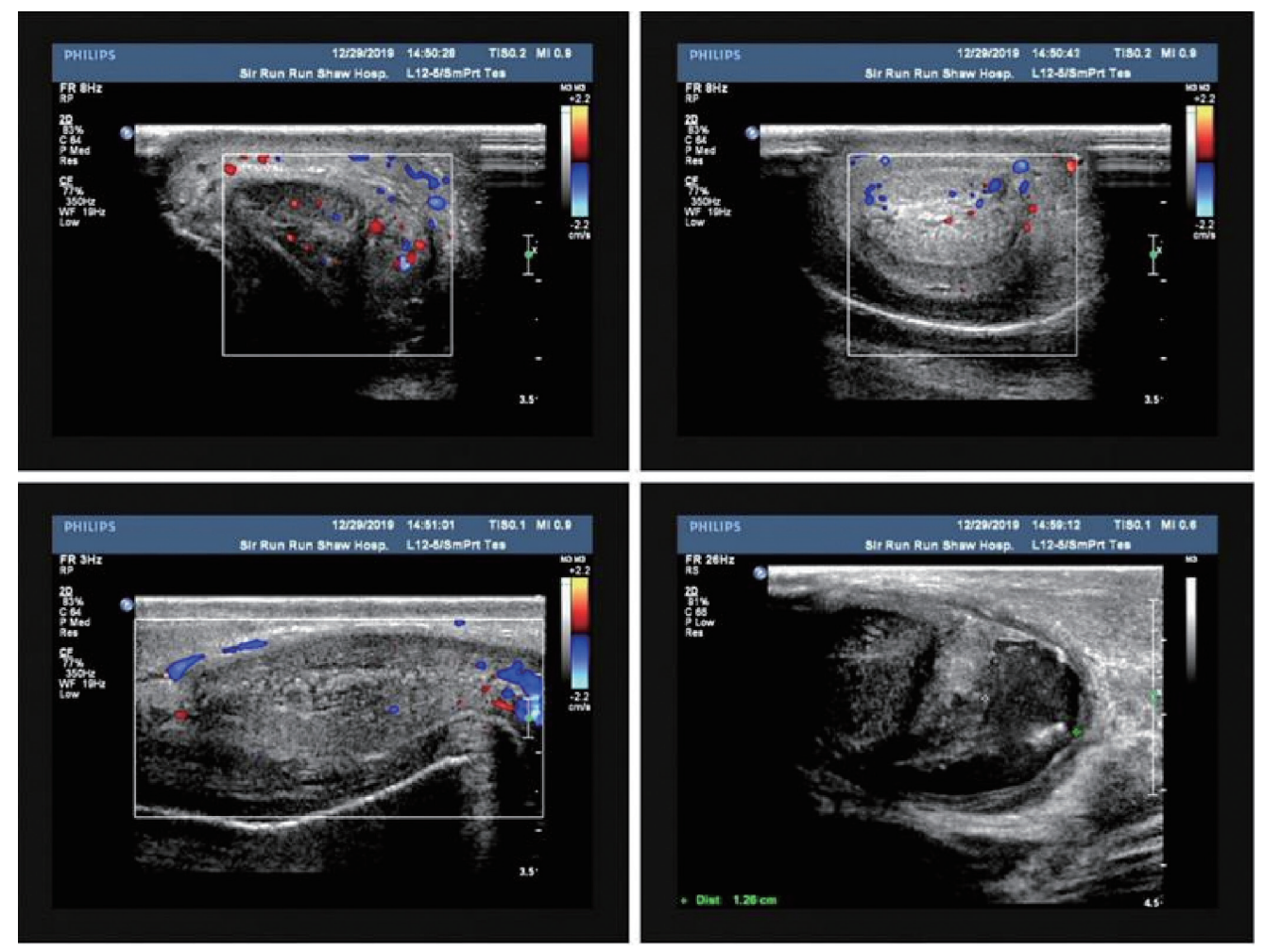

Figure 1 B-ultrasound showed that blood flow signals could be detected in the penile cavernous body, and irregular liquid dark areas with about $1.3 \mathrm{~cm}$ were detected behind the root of the penile cavernous body. The sound transmission was poor and fine light spots were visible.

for the patient of penile fracture with complete urethral injury. Here, we present a case with bilateral penile fracture and complete urethral injury in accordance with the CARE reporting checklist (available at http://dx.doi.org/10.21037/ tau-20-1155).

\section{Case presentation}

A 43-year-old male was admitted to the hospital because of "trauma to the genital and dysuria". The patient presented with trauma to the genital after sexual intercourse for 6 hours. Subsequently, the patient developed swelling, congestion, and progressive worsening of the penis with urethral bleeding and dysuria. The penile appeared swelling and the foreskin appeared obvious edema. There was tenderness on palpation of the penile which indicated penile fracture with possible urethral injury. All other examinations were normal except the area of pathology. In addition, the patient did not receive other medical interventions before. He had hemorrhoid surgery ten years ago and recovered completely, while family and psycho-social history was normal.

B-ultrasound showed that blood flow signals could be detected in the penile cavernous body, and irregular liquid dark areas with about $1.3 \mathrm{~cm}$ were detected behind the root of the penile cavernous body. The sound transmission was poor and fine light spots were visible (Figure 1). Then, he was diagnosed of penile fracture with complete urethral injury and prepared for the emergency surgery.

Urethral microscopy revealed that urethral rupture and local hematoma approximately $7 \mathrm{~cm}$ from the urethral orifice, and distal urethra was not visible. Then, we made a circular incision at the base of penis to separate the wound and clear the hematoma. More, intraoperative found that the urethra was completely broken, combined with a $1.5 \mathrm{~cm}$ slit in the ventral tunica albuginea of the left cavernous body 

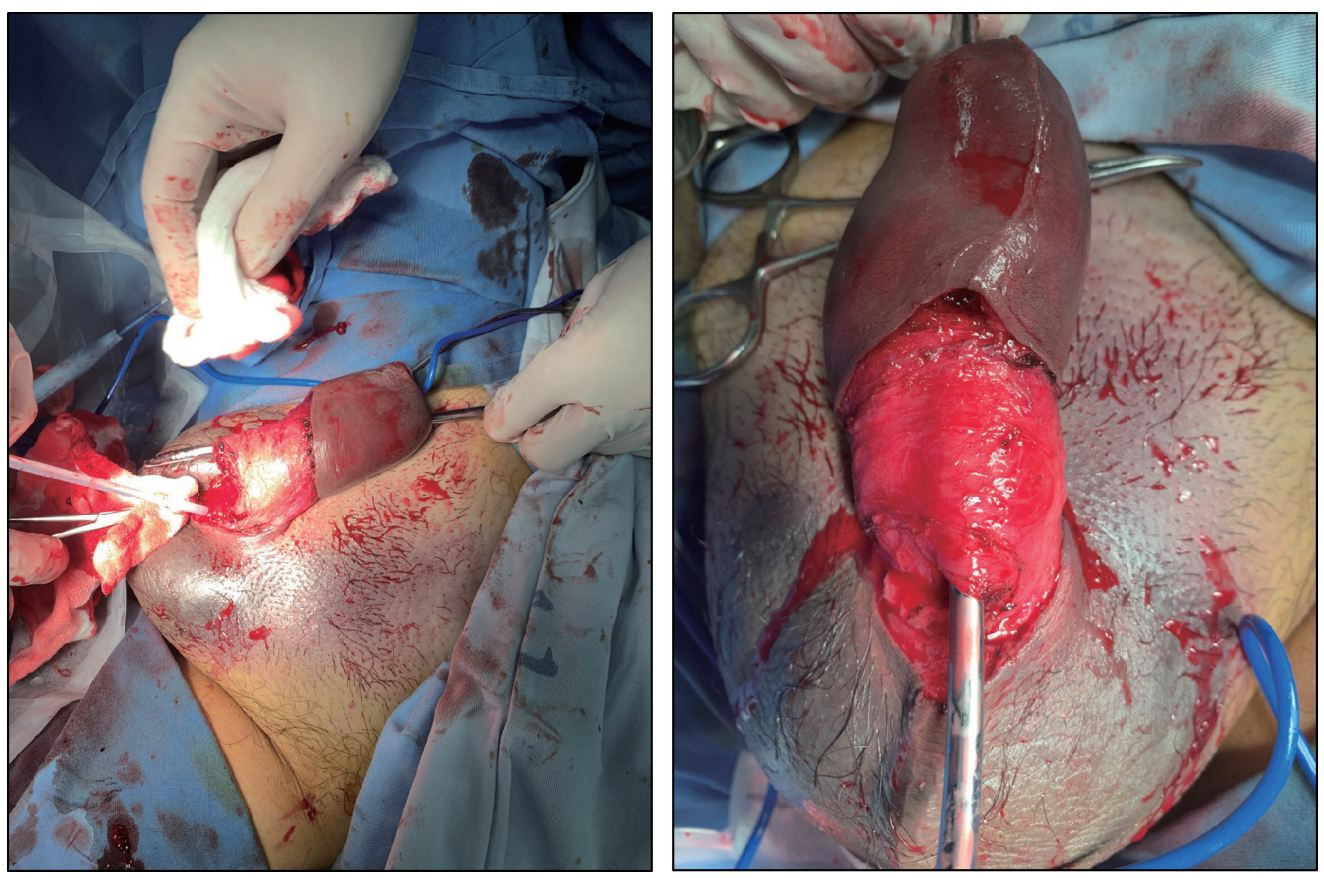

Figure 2 The figure shows the penile fracture with complete urethral injury.

and a $0.7 \mathrm{~cm}$ slit in the ventral tunica albuginea of the right cavernous body (Figure 2). Local hematomas were formed with obvious edema of the tissues. The rupture of urethra was separated and exposed.

The distally and proximally ventral urethra were cut $0.5 \mathrm{~cm}$ longitudinally for suturing. Bilateral cavernous body injury was repaired with $4-0$ absorbable sutures. Then a $16 \mathrm{~F}$ catheter was placed at the stump of the proximal urethra and a metal urethra probe was placed at the distal urethra, the posterior wall of urethra was anastomosed with 4-0 absorbable sutures firstly, then insert the catheter from the urethra orifice to suture the anterior wall of urethra. Then the penile skin closed in a simple interrupted fashion. After surgery, piperacillin tazobactam was given $4.5 \mathrm{~g}$ intravenously for 8 hours to resist infection. The patient recovered well and discharged successfully on the 3 rd day after the operation. Catheter was removed after 3 weeks of repair and urethroscopy indicated that the mucous membrane of the urethra was smooth, no stenosis was seen, and no vegetation was seen (Figure 3). Patient urinated smoothly and still had normal erectile function 2 months later. The whole process of this patient treatment was described in the Figure 4.

All procedures performed in studies involving human participants were in accordance with the ethical standards of the institutional and national research committee and with the Helsinki Declaration (as revised in 2013). Written informed consent was obtained from the patient for publication of this study and any accompanying images.

\section{Discussion}

Penile fracture occurs in the setting of penile trauma to the erect penis, most often during sexual intercourse. Symptoms and signs are typical. They associate cracking sound and acute pain of the erect penis rapidly followed by detumescence (3). Penile fracture with urethral rupture is a rare condition. The urethral rupture can be partial or complete and the incidence varies from $1 \%$ to $38 \%(3,5)$. However, $50 \%$ of cases of urethral injury are clinically asymptomatic and the lesion is found accidentally during ultrasound or intraoperatively. Ultrasonography is also a 

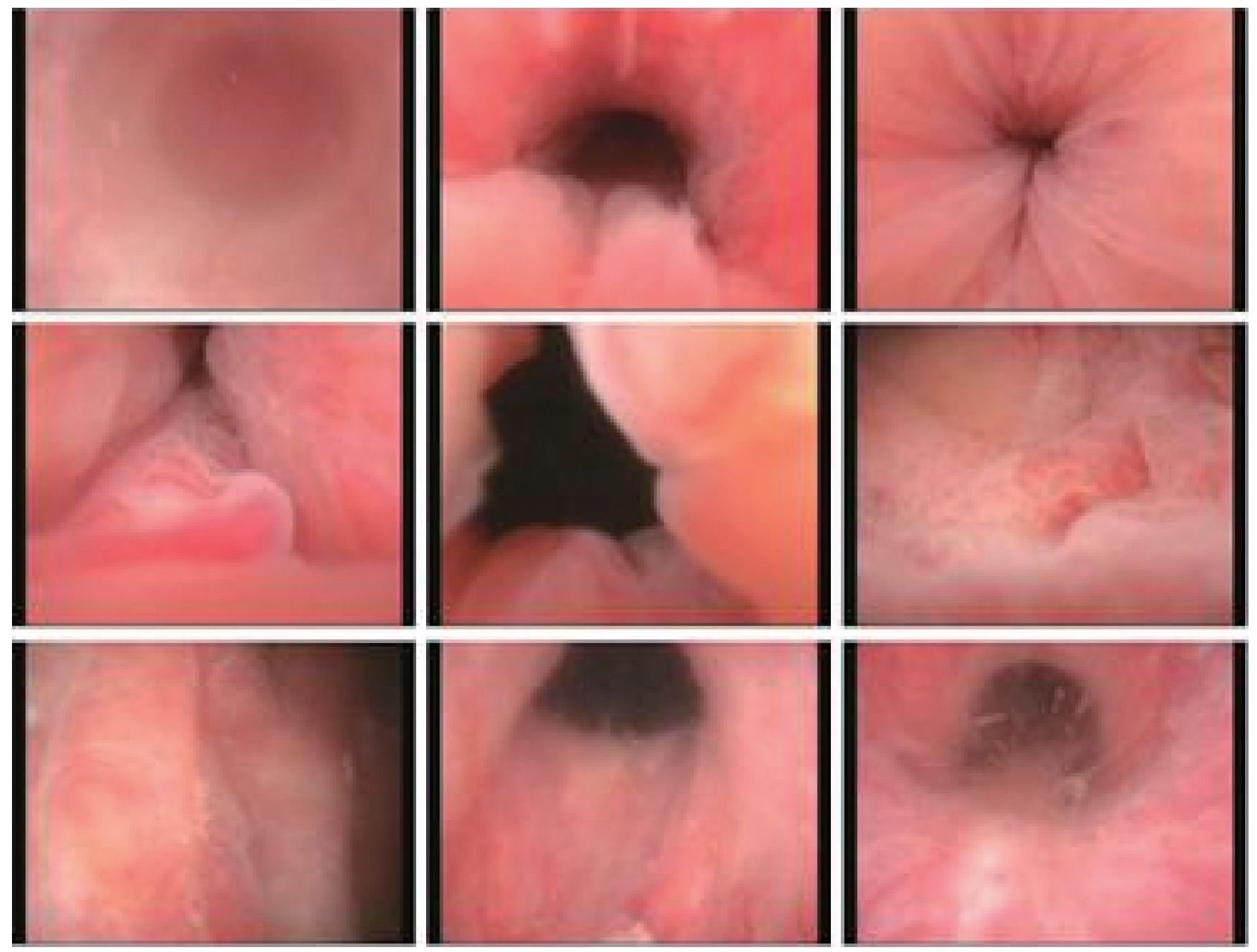

Figure 3 After 3 weeks, urethroscopy indicated that the mucous membrane of the urethra was smooth; no stenosis and no vegetation was seen.

useful tool in confirming the location of the albuginea tear and identifying the presence of any concomitant urethral injury, helping the surgeon to choose the best surgical approach (6). In this case, the patient showed the typical symptoms after sexual intercourse. With the rapid and accurate diagnose, we performed the surgery to avoid the adverse events. The patient was satisfied with the treatment and said he would be careful when he had sexual intercourse. Due to our cultural reasons, the public's awareness of penile fractures was relatively lacking. Some people even delayed their illness and had many complications.
Treatment of penile fractures has always been a controversial issue. In the past, patients were recommended to undergo non-surgical treatment, including bed rest, elastic dressing, indwelling catheter, and ice pack cold compress for 24 to $48 \mathrm{~h}$, and the use of oxyphenbutazone, and diazepam to inhibit erection (7). However, $10 \%$ to $30 \%$ patients had erectile function after receiving nonsurgical treatment $(8,9)$. At present, immediate surgery for the urethral injury in the penile fracture is recommended by most authors. Ahmed et al indicated most patients (91.6\%) achieved an adequate erection after immediate surgery 


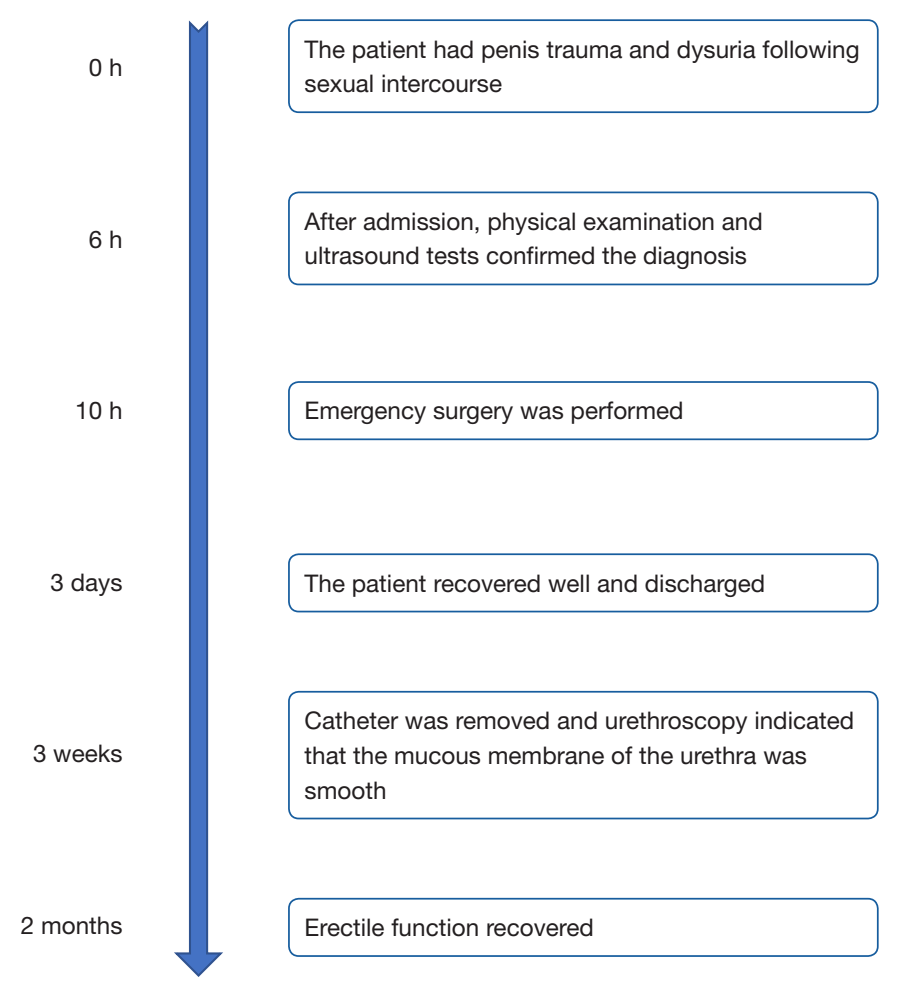

Figure 4 The whole process of the case treatment.

except two cases who felt mild erectile dysfunction (10). Even in the delayed presentation, delayed surgery also showed the satisfactory outcome $(11,12)$. For the penile fracture with urethral injury, bilateral corporal rupture should also be investigated when doing the surgery repair $(13,14)$. On the long-term follow-up, most of the patients maintained their normal erectile and voiding functions without complications after reconstruction of both corpora cavernous and urethra $(15,16)$ (Table 1). In this case, immediate surgery was adopted since the penile fracture was confirmed. An absorbable suture was suggested to repair the tunica defect. Buck's fascia and urethra should also undergo repair. Postoperative outcome was satisfactory after three weeks, consistent with previous reports $(15,17)$. This report also adds the evidence that immediate surgery to repair both corpora cavernous and urethra for penile fracture with complete urethral injury is the proper treatment.

In this case, clinical presentation and ultrasound examinations were important to diagnosis the penile fracture. Furthermore, during the surgery, tunica albuginea must be carefully checked to avoid missing the injury; both corpora cavernous and urethra should be repaired. Ventral midline incision of the penis is chosen for surgery approach in this case. The advantage of this incision method was easy to explore the root of the cavernous penis where penis injuries often happen. More importantly, removal of hematoma, repair ruptured tunica albuginea, and check any possible deep damage sites including urethral injury was convenient through this surgical approach. The limitation of this case was that the patient did not follow-up after two months.

\section{Conclusions}

In conclusion, penile fracture is a relatively rare urological emergency, particularly with complete urethral injury. In the presence with hematuria or dysuria, urethral injury should be suspected. Immediate surgical repair of both urethral and corporal is the proper treatment and would have satisfactory outcome. 
Table 1 Previous research on the penile fractures

\begin{tabular}{|c|c|c|c|c|c|c|}
\hline Study & $\begin{array}{l}\text { Clinical } \\
\text { manifestation }\end{array}$ & Imaging features & Therapies & Time to treat & $\begin{array}{l}\text { Length of } \\
\text { follow-up }\end{array}$ & Outcomes \\
\hline $\begin{array}{l}\text { Ateyah et al. } \\
(10), 2007\end{array}$ & $\begin{array}{l}\text { Cracking sound, } \\
\text { pain, hematoma, } \\
\text { detumescence or } \\
\text { hematuria }\end{array}$ & $\begin{array}{l}\text { The ultrasound showed } \\
\text { irregular defects at the site of } \\
\text { cavernosa rupture }\end{array}$ & Surgery & $5.2 \pm 3.7$ hours & 6 months & $\begin{array}{l}91.6 \% \text { patients } \\
\text { achieved an adequate } \\
\text { erection, } 8.4 \% \text { patients } \\
\text { felt mild erectile } \\
\text { dysfunction. } 41.6 \% \\
\text { patients had penile } \\
\text { nodules }\end{array}$ \\
\hline $\begin{array}{l}\text { Mercado- } \\
\text { Olivares } \\
\text { et al. (14), } \\
2018\end{array}$ & $\begin{array}{l}\text { Severe pain, penis } \\
\text { was swollen, } \\
\text { deformed, and with } \\
\text { signs of ecchymosis }\end{array}$ & $\begin{array}{l}\text { Two ventral irregularities were } \\
\text { found }\end{array}$ & Surgery & 4 hours & 90 days & $\begin{array}{l}\text { The patient had a } \\
\text { favorable recovery and } \\
\text { was discharged on the } \\
\text { third postoperative day } \\
\text { without complications }\end{array}$ \\
\hline $\begin{array}{l}\text { Yunusa et al. } \\
\text { (12), } 2019\end{array}$ & $\begin{array}{l}\text { Swelling penile; } \\
\text { painful micturition } \\
\text { and hematuria }\end{array}$ & $\begin{array}{l}\text { Bulging hematoma on } \\
\text { the right mid shaft and an } \\
\text { approximate } 4 \mathrm{~cm} \text { transverse } \\
\text { defect on the ventral surface } \\
\text { of the right tunica albuginea } \\
\text { with complete urethral defect } \\
\text { at the same spot }\end{array}$ & Surgery & 2 weeks & 2 weeks & $\begin{array}{l}\text { There was immediate } \\
\text { straightening of the } \\
\text { penis after the repairs } \\
\text { and the urethra was } \\
\text { intact }\end{array}$ \\
\hline
\end{tabular}

\section{Acknowledgments}

Funding: This work was supported by Medical Health Science and Technology Project of Zhejiang Provincial Health Commission (2017KY420).

\section{Footnote}

Reporting Checklist: The authors have completed the CARE reporting checklist. Available at http://dx.doi.org/10.21037/ tau-20-1155
Peer Review File: Available at http://dx.doi.org/10.21037/ tau-20-1155

Conflicts of Interest: All authors have completed the ICMJE uniform disclosure form (available at http://dx.doi. org/10.21037/tau-20-1155). The authors have no conflicts of interest to declare.

Ethical Statement: The authors are accountable for all aspects of the work in ensuring that questions related to the accuracy or integrity of any part of the work are 
appropriately investigated and resolved. All procedures performed in studies involving human participants were in accordance with the ethical standards of the institutional and/or national research committee(s) and with the Helsinki Declaration (as revised in 2013). Written informed consent was obtained from the patient.

Open Access Statement: This is an Open Access article distributed in accordance with the Creative Commons Attribution-NonCommercial-NoDerivs 4.0 International License (CC BY-NC-ND 4.0), which permits the noncommercial replication and distribution of the article with the strict proviso that no changes or edits are made and the original work is properly cited (including links to both the formal publication through the relevant DOI and the license). See: https://creativecommons.org/licenses/by-nc-nd/4.0/.

\section{References}

1. Diaz KC, Cronovich H. Penis Fracture. StatPearls. Treasure Island (FL): StatPearls Publishing, 2020.

2. Kati B, Akin Y, Demir M, et al. Penile fracture and investigation of early surgical repair effects on erectile dysfunction. Urologia 2019;86:207-10.

3. Derouiche A, Belhaj K, Hentati H, et al. Management of penile fractures complicated by urethral rupture. Int J Impot Res 2008;20:111-4.

4. Eke N. Fracture of the penis. Br J Surg 2002;89:555-65.

5. Muentener M, Suter S, Hauri D, et al. Long-term experience with surgical and conservative treatment of penile fracture. J Urol 2004;172:576-9.

6. Falcone M, Garaffa G, Castiglione F, et al. Current Management of Penile Fracture: An Up-to-Date Systematic Review. Sex Med Rev 2018;6:253-60.

Cite this article as: Ge G, Wang H, Chen Y, Li G, Ma L. Complete urethral injury in the penile fracture: a case report and literature review. Transl Androl Urol 2021;10(2):969-975. doi: 10.21037/tau-20-1155
7. Jallu A, Wani NA, Rashid PA. Fracture of the penis. J Urol 1980;123:285-6.

8. Gamal WM, Osman MM, Hammady A, et al. Penile fracture: long-term results of surgical and conservative management. J Trauma 2011;71:491-3.

9. Ozen HA, Erkan I, Alkibay T, et al. Fracture of the penis and long-term results of surgical treatment. Br J Urol 1986;58:551-2.

10. Ateyah A, Mostafa T, Nasser TA, et al. Penile fracture: surgical repair and late effects on erectile function. J Sex Med 2008;5:1496-502.

11. Waseem M, Upadhyay R, Kapoor R, et al. Fracture of the penis: an atypical presentation. Int J Emerg Med 2013;6:32.

12. Yunusa B, Wullie K, Willie SE, et al. Penile Fracture: Delayed Presentation, Primary Urethral Repair and Satisfactory Outcome. Case Rep Urol 2019;2019:1456914.

13. De Stefani S, Stubinski R, Ferneti F, et al. Penile fracture and associated urethral injury. ScientificWorldJournal 2004;4 Suppl 1:92-9.

14. Mercado-Olivares F, Grandez-Urbina JA, Farfan-Daza G, et al. Case Report: Double penile fracture. F1000Res 2018;7:1828.

15. Raheem AA, El-Tatawy H, Eissa A, et al. Urinary and sexual functions after surgical treatment of penile fracture concomitant with complete urethral disruption. Arch Ital Urol Androl 2014;86:15-9.

16. Nale D, Bojanić N, Nikić P. Penile fracture: a rare case of simultaneous rupture of the one corpus cavernosum and complete urethral rupture. Vojnosanit Pregl 2015;72:60-2.

17. Barros R, Guimarães M, Nascimento C, Jr., et al. Penile refracture: a preliminary report. Int Braz J Urol 2018;44:800-4. 